\title{
Heartbeat: time for action to eliminate sex disparities in management and outcomes of patients with an acute coronary syndrome
}

Sex differences in the clinical presentation of patients with chest pain and acute coronary syndromes (ACS) are well known. Even so, sex disparities persist in management and outcomes of women with chest pain. To better understand whether sexdifferences in the initial assessment of patients with non-traumatic chest pain contribute to later adverse clinical outcomes, Mnatzaganian and colleagues ${ }^{1}$ retrospectively analysed data on 54138 adults presenting to three emergency departments (EDs) in Melbourne with non-traumatic chest pain. On multivariable analysis, women (49\% of patients) were $18 \%$ less likely to be triaged as urgent, $16 \%$ less likely to be examined by a physician within 1 hour, 20\% less likely to have a troponin measured and 36\% less likely to be admitted to a specialised care unit. Yet, these women clearly were even sicker than the men with a $35 \%$ higher risk of death in the ED and a 36\% higher risk of death during that hospitalisation. (figure 1)

As stated so clearly in the accompanying editorial by Mackay ${ }^{2}$ : 'these discouraging findings should not come as a surprise to the cardiology community. Study after study, though perhaps drawn from slightly different populations and examining slightly different outcomes, has reached similar conclusions. But, time's up. Mnatzaganian and colleagues' work $^{1}$ should provide strong motivation to design and test interventions aimed at improving the care provided to women with symptoms of ACS in the first hours after presentation so that their overall outcomes can be improved.'

Sex differences in normal cardiac dimensions also have not been adequately addressed in many of the 'normal value' tables used in imaging laboratories around the world. Changes in cardiac dimensions with ageing, while possibly not 'normal' also are typical and sex-differences with ageing have not been well documented. In a series of 2505 patients over age 55

Correspondence to Professor Catherine M Otto, Division of Cardiology, University of Washington, Seattle, WA 98195, USA; cmotto@uw.edu

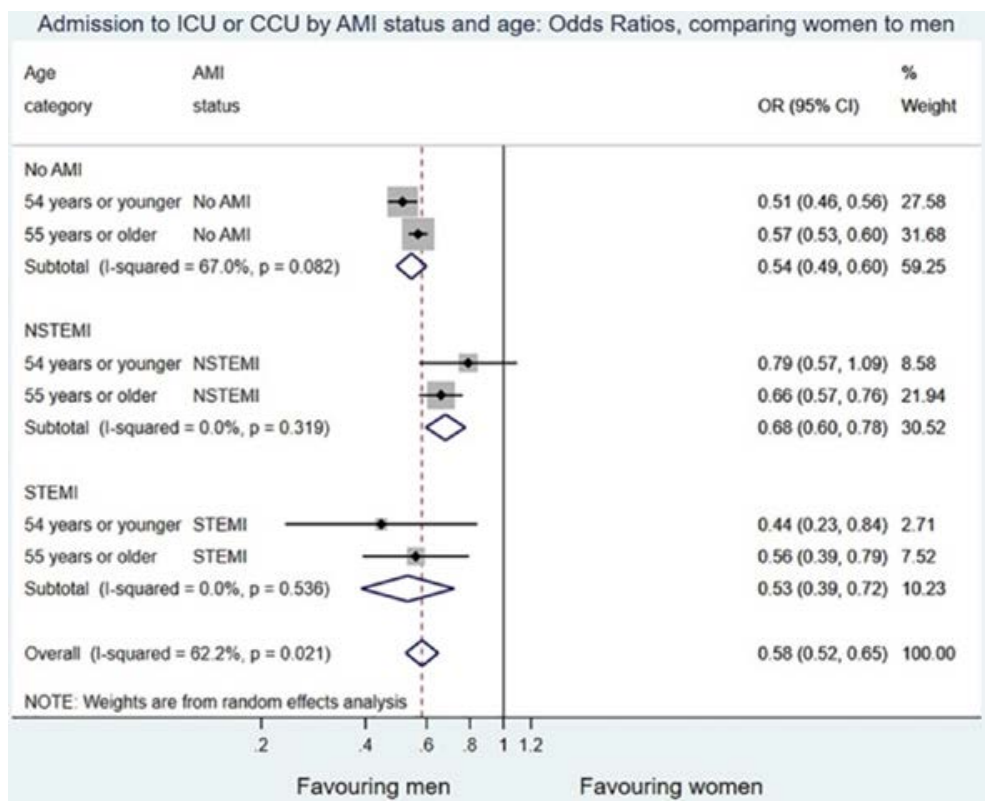

Figure 1 Admission to ICU or CCU by median age and emergency department diagnosis of acute myocardial infarction: $\mathrm{OR}(95 \% \mathrm{CI})$, comparing women with men. $\mathrm{AMI}$, acute myocardial infarction; CCU, coronary care unit; ICU, intensive care unit; NSTEMI, non-ST elevation myocardial infarction; STEMI, ST elevation myocardial infarction.

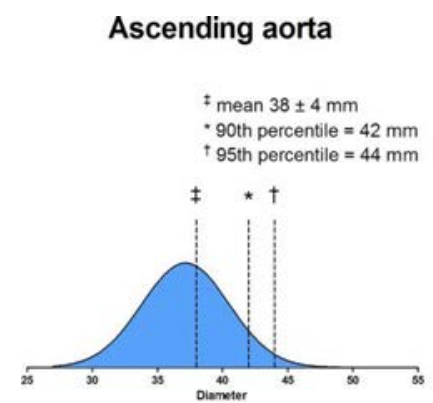

Descending aorta
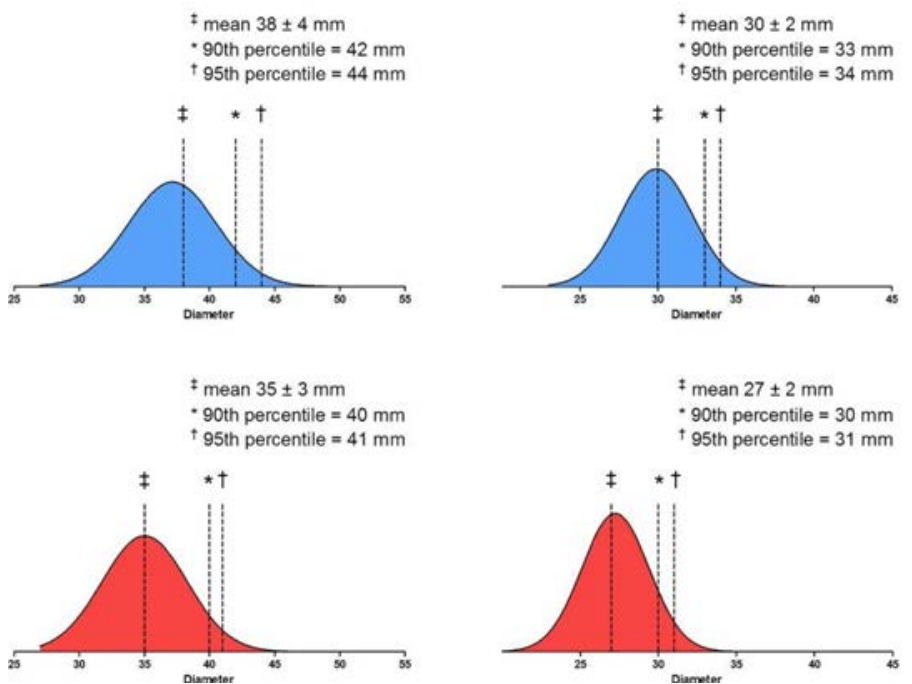

Men

Women

Figure 2 Distribution of the ascending and descending aortic diameters for both men (blue) and women (red), marking mean values, the 90th and 95th percentiles. 
Table 1 Comparisons between superiority and non-inferiority trials

\begin{tabular}{|c|c|c|}
\hline Characteristics & Superiority trials & Non-inferiority trials \\
\hline Null hypothesis & New treatment not superior to standard treatment/placebo & $\begin{array}{l}\text { New treatment inferior to standard } \\
\text { treatment }\end{array}$ \\
\hline Alternative hypothesis & New treatment is better than standard treatment/placebo & $\begin{array}{l}\text { New treatment non-inferior to standard } \\
\text { treatment }\end{array}$ \\
\hline Non-inferior margin & Not applicable & Predetermined \\
\hline Sequential testing & Not possible & Can be performed \\
\hline Significance level & $\mathrm{P}<0.05$ (two-sided) & $\mathrm{P}<0.025$ (one-sided) \\
\hline Comparator & Standard treatment or placebo & Standard treatment (seldom placebo) \\
\hline Possible outcomes & $\begin{array}{l}\text { 1. New treatment superior (or inferior) to standard treatment/placebo } \\
\text { 2. Inconclusive }\end{array}$ & See figure 1 \\
\hline Subgroup analyses & Possible & Possible \\
\hline
\end{tabular}

years (mean age 69 years) enrolled in the population-based Rotterdam Study, Bons and colleagues ${ }^{3}$ found that aortic diameters measured by non-contrast computed tomographic imaging were significant larger in men compared to women. In addition, mean and 95\% CIs for aortic

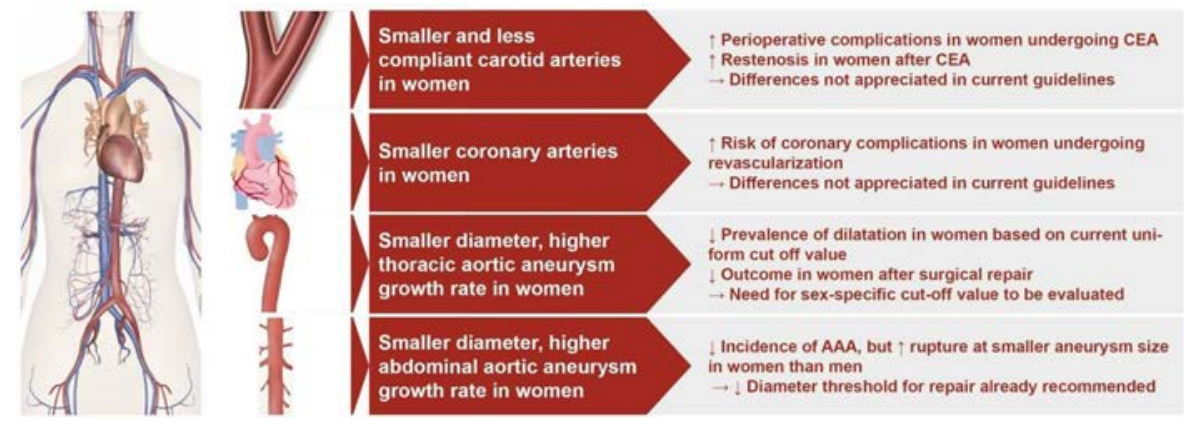

Figure 3 Sex differences in vascular properties and clinical implications. AAA, abdominal aortic aneurysm; CEA, carotid endarterectomy.

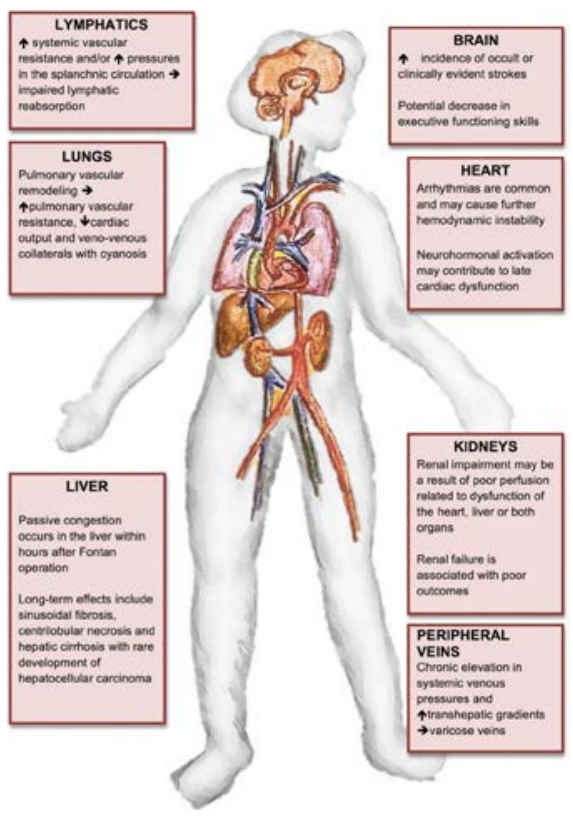

Figure 4 Multiorgan dysfunction later after Fontan operation (reproduced with permission from Book et $a l^{10}$ ). diameters in this cohort of patients were considerably larger than normal values derived from younger populations. Mean diameter of the ascending aorta was 38 $\mathrm{mm}$ in men and $35 \mathrm{~mm}$ in women with $18.6 \%$ of men and $5.9 \%$ of women having an aortic diameter larger than $40 \mathrm{~mm}$.(-

figure 1) A larger aortic diameter was associated with age, height, weight and traditional cardiovascular risk factors, except for diabetes (figure 2).

In my view, we should no longer be using diameter thresholds derived from younger populations to diagnose the presence of 'aortic dilation' in women or men over age 55 years. Over-diagnosis results in needless patient anxiety and excessive sequential imaging. Rather than using aortic diameter thresholds derived from younger populations, we should focus on identifying which patients are at risk of aortic dissection; possibly by considering aortic length, not just diameter, or by increased attention to genetic and clinical risk factors, including hypertension. ${ }^{45}$ In the accompanying editorial, Groepenhoff and den Ruijter ${ }^{6}$ point out several other differences in vascular properties between men and women related to coronary, carotid and aortic disease (figure 3 ). Clearly, we need to consider all these factors in clinical decision making, along with aortic size compared to age and sex stratified normal values.

Further support for the increased cardiovascular risk associated with feeling lonely is provided by a study in this issue of Heart of over 13000 patients with heart disease. ${ }^{7}$ In patients who felt lonely the risk of all-cause mortality at 1 year was almost threefold higher in men and twofold higher in women compared to patients who did not feel lonely. However, living along cannot be equated with loneliness because while living alone was associated with a higher risk of cardiac events in men, women living alone were not at higher risk.

In a concise and readable review article, Leung and colleagues ${ }^{8}$ explain the design and interpretation of non-inferiority trials. Both clinicians and trainees will want to read this article to better understand the pitfalls of this type of study design, as well as the rationale for choosing a noninferiority over a superiority trial (table 1 ). They emphasise that we should focus on effect size and confidence intervals, not $p$ values, in interpreting the significance of the data presented.

Patients with complex congenital heart disease resulting in a single functional ventricle often are treated early in life with a palliative Fontan procedure to connect the systemic venous return directly to the pulmonary artery, without an intervening ventricle. As these patients grow to adulthood, clinical cardiologists are increasingly expected to provide day-to-day clinical management, often in collaboration with subspecialists in adult congenital heart disease. A review article ${ }^{9}$ in this issue of Heart provides an overview on management of the adult Fontan patient, including possible complications and urgent issues (figure 4).

The Heart homepage now has a dedicated section highlighting our Podcasts. You can listen right from the homepage, 
Podcasts

\section{Heart}

HEART PODCASTS

A heart failure extravaganza!

Released on: $2 / 12 / 2019$

Length: 0:36:30

In this double-length episode of the Heart podcast, James Rudd is joined by Dr Stephen Pettit from Royal

Papworth Hospital, Cambridge. They discuss cardiogenic shock, HFPEF, new drugs for heart failure,

optimisation after CRT and why heart failure is a great choice of speciality for young cardiologists.

Our next podcast episode will be released in early January 2020

If you enjoy the show, please subscribe to the podcast to get episodes automatically downloaded to your phone and computer. Also, please consider leaving us a review at

https:/itunes.apple.com/gb/podcast/heart-podcast/id445358212?mt=2

Link to Dr Pettit's profile - https://royalpapworth.nhs.uk/consultant-profiles/dr-stephen-pettit

Share: 1 ff Download: 1 Subscribe: 20

\section{Figure 5}

access free links to the papers we discuss on the show and discover our entire backcatalogue of more than 150 episodes. In these dynamic interviews, James Rudd dives beneath the simple text of the published paper to elicit the authors' insights into the interpretation and clinical impact of their work. These podcasts are easy to listen to on your phone, tablet, in the car or at your computer. Here's a video explaining how to listen to the Podcast: https://www. youtube.com/watch? $\mathrm{v}=$ UG3APAv9LMg Join the many thousands of people enjoying each episode, and if you are not yet a Heart Podcast listener, give it a try! (figure 5)

Contributors All authors contributed.

Funding The authors have not declared a specific grant for this research from any funding agency in the public, commercial or not-for-profit sectors.
Competing interests None declared.

Patient consent for publication Not required.

Provenance and peer review Commissioned; internally peer reviewed.

(C) Author(s) (or their employer(s)) 2020. No commercial re-use. See rights and permissions. Published by BMJ.

\section{D) Check for updates}

To cite Otto CM. Heart 2020;106:89-91.

Heart 2020;106:89-91.

doi:10.1136/heartjnl-2019-316403

\section{ORCID iD}

Catherine M Otto http://orcid.org/0000-0002-05279392

\section{REFERENCES}

1 Mnatzaganian G, Hiller JE, Braitberg G, et al. Sex disparities in the assessment and outcomes of chest pain presentations in emergency departments. Heart 2020;106:111-8.

\section{Recent podcasts}

A heart failure extravaganza! Released on: 2/12/2019 Length: 0:36:30

Frequent PVCs - to treat or not to treat? Released on: 15/11/2019 Length: 0:16:05

Napping - good for the heart? Released on: $1 / 11 / 2019$ Length: 0:16:59

Pre-operative cardiac testing - how should we do it? Released on: 15/10/2019 Length: 0:24:05

Heart failure with preserved ejection fraction - which treatments work?

Released on: 1/10/2019 Length:0:13:07

\section{All related podcasts}

